\title{
Research on Fertilizer Efficiency of Continuous Cropping Greenhouse Cucumber Based on DEA Model
}

\author{
Xiaohui Yang ${ }^{1}$, Yuxiang Huang ${ }^{2}$, Shuqin $\mathrm{Li}^{1,}$, and Sheng Huang ${ }^{2}$ \\ ${ }^{1}$ College of Information Engineering, Northwest A\&F University, Yangling, China \\ ${ }^{2}$ College of Mechanical and Electronic Engineering, \\ Northwest A\&F University, Yangling, China \\ hyx@nwsuaf .edu.cn
}

\begin{abstract}
Fertilizer efficiency directly affects the production of continuous cropping greenhouse cucumber. So analyzing the fertilizer efficiency is of great significance in providing decision-making support for fertilization of greenhouse cucumber. By establishing the DEA models of continuous cropping greenhouse cucumber and taking existing data samples as study objects, the problems of fertilizer efficiency in traditional fertilization, target yield fertilization and mathematical model fertilization were studied. And the technical efficiency, pure technical efficiency, scale efficiency and redundancy rates of the three types of fertilization methods have been obtained by analyzing the relationship of three inputs $\left(\mathrm{N}, \mathrm{P}_{2} \mathrm{O}_{5}, \mathrm{~K}_{2} \mathrm{O}\right)$ and one output (Yield). Through analyzing fertilizer efficiency of the three types of fertilization methods, it could get the sort by the size of mathematical model fertilization, target yield fertilization and traditional fertilization. The results showed that the method of mathematical model fertilization is more reasonable in fertilizing and the DEA method is efficient and practical in analyzing the fertilizer efficiency.
\end{abstract}

Keywords: Greenhouse cucumber, Fertilization, Efficiency, DEA method.

\section{Introduction}

Due to the limited understanding, the dependence on experience and the lack of the guidance of scientific fertilization theory, problems, such as excessive fertilization and low fertilize efficiency, are universally existent in production practice of greenhouse cucumber in China. Meanwhile, owing to the higher economic benefits of planting greenhouse cucumber, the pursuit of high yield and utilization ratio of installations, the continuous cropping of greenhouse cucumber is fairly common. But continuous cropping causes many problems, such as soil nutrient imbalance and deterioration of soil properties. Fertilizing reasonably and balancing the soil nutrient are the fundamental ways to improve the fertilizer utilization ratio, reduce pollution, and solve the problem of continuous cropping in sunlight greenhouse. So the guidance of scientific

* Corresponding author. 
fertilization theory should be needed to avoid fertilizer over-using and fertilizer improper-applying.

Data Envelopment Analysis (DEA) is an effective optimization method used for measuring the relative efficiency of Decision Making Unit (DMU) (Charnes, A., et al., 1978). $C^{2} R$ model and BCC model are the two most commonly used DEA models. Suppose there are $n$ DMUs, and each DMU has $m$ inputs and $k$ outputs, then the technical efficiency(TE), pure technical efficiency(PTE), scale efficiency(SE), re-

dundancy rates(RR) of each DMU can be calculated by using the $C^{2} R$ model and BCC model (Quanling Wei ,et al., 2004; Shoukang Qin, et al., 2003).

In this paper, the fertilize efficiency analysis models of continuous cropping greenhouse cucumber were established. Based on the samples from [1] (Liying Wang, et al., 2008) and DEA method (Charnes, A., et al., 1978), the fertilization efficiency of input and output of three fertilization methods (mathematical model fertilization, target yield fertilization and traditional fertilization)were studied from the views of TE, PTE, SE and RR. Where TE and PTE reflect the relation between fertilizer rate and the yield of greenhouse cucumber under the assumption of that the scale benefit is constant and mutative, respectively. SE is the ratio of TE to PTE. And RR is the ratio of input slacks to the actual input. And the efficiency of three fertilization methods were compared and analyzed. This paper aims at finding out methods to improve the fertilization efficiency of greenhouse cucumber and provide information for fertilization decision-making and practice.

\section{Materials and Methods}

\subsection{Data Resources}

In this paper, six 3-years continuous cropping plots were used for example to analyze the fertilize efficiency of greenhouse cucumber with the help of DEA Solver3.0 software. And the data of three inputs $\left(\mathrm{N}, \mathrm{P}_{2} \mathrm{O}_{5}, \mathrm{~K}_{2} \mathrm{O}\right)$ and one output (Yield) from [1] were took as samples. The calculation formulas for the fertilizer rate of mathematical model fertilization and target yield fertilization are available from [5] (Lunshou Chen, Jingling Lu, 2002) and [6] (Yancai Zhang, et al., 2005).

\subsection{Hypotheses}

To simplify, the fertilize efficiency analysis models of continuous cropping greenhouse cucumber were established under two hypotheses as follow: (1) $\mathrm{N}, \mathrm{P}_{2} \mathrm{O}_{5}, \mathrm{~K}_{2} \mathrm{O}$ are the major factors that affect the yield levels of greenhouse cucumber. (2) For different planting years and seasons, soil nutrient of different plots is the same.

\subsection{Procedures}

The $C^{2} R$ model and BCC mode were used to establish the fertilize efficiency analysis models of continuous cropping greenhouse cucumber. For each plot, its TE, PTE, SE 
and RR were evaluated and analyzed. Each field (DMU) has three inputs $\left(\mathrm{N}, \mathrm{P}_{2} \mathrm{O}_{5}\right.$, $\mathrm{K}_{2} \mathrm{O}$ ) and one output (yield). If $\theta=1$ ( $\theta$ is the score of fertilizer efficiency), it indicates that the field (DMU) is a DEA effective unit, and its TE or PTE reach the highest level. If $\theta<1$, it declares that the field (DMU) is not a DEA effective unit and its input of fertilizer is unreasonable. For a non DEA efficient $\left(\mathrm{C}^{2} \mathrm{R}\right.$ or BCC) DMU, its input and output slacks and RR can be calculated by using the projection principle and related formulas.

Comparing the value of $\theta$ of the same field which was under the same continuous cropping years and three types of fertilization, it can find out that which type of fertilization is more

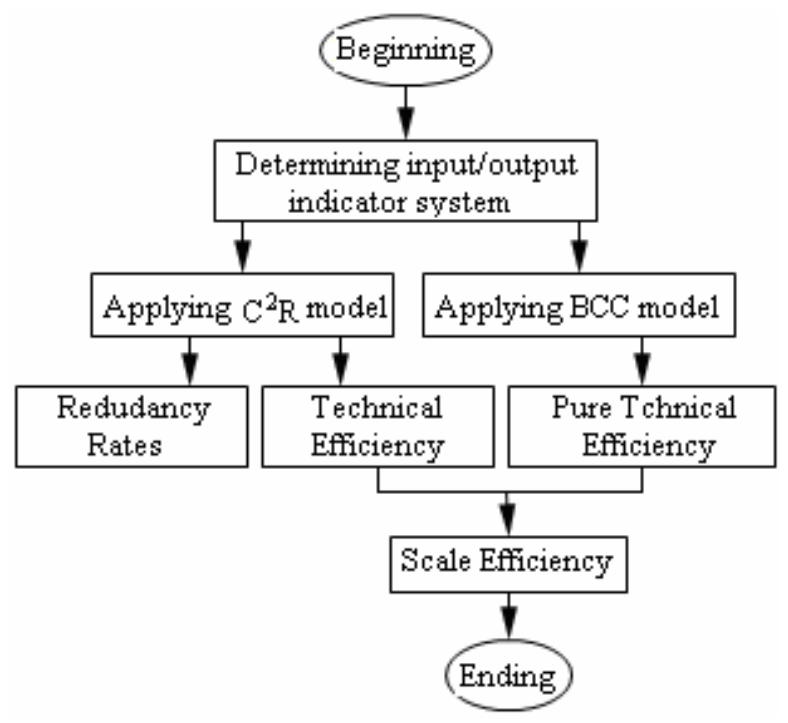

Fig. 1. The frame of analysis model for the greenhouse cucumber input-output efficiency reasonable or the unreasonable reasons of the irrational one. By comparing the RR of the same field, it can be analyzed how much input of $\mathrm{N}, \mathrm{P}_{2} \mathrm{O}_{5}, \mathrm{~K}_{2} \mathrm{O}$ can be saved and which input should be adjusted. Besides, the fertilize efficiency of the same field under different types of fertilization and different continuous cropping years can be compared. The analysis steps were showed in the Figure 1.

\section{Results and Discussion}

By calculating the TE, PTE, SE and RR of greenhouse cucumber of three types of fertilization, the results were reported in table 1.In addition, the fertilization efficiency of three types of fertilization was described in the figure 2, figure 3 and figure 4.

\subsection{The Fertilization Efficiency without Considering the Diversity of Fertilize Methods}

According to the table 1 and regarding the technical efficiency, there are 4 DEA effective units, accounting for 22.22 percent of the total samples. And the technical efficiency of 9 units exceeds the average of the samples' TE which is 0.6826 , about half of all. To the pure technical efficiency, there are 7 DEA effective units, accounting 
for 38.89 percent of the total samples. And the pure technical efficiency of 14 units outperforms the average of the samples' PTE which is 0.8579 , about 77.78 percent of all. And to the scale efficiency, there are 4 DEA effective units, accounting for 22.22 percent of the total samples. And the scale efficiency of 9 units exceeds the average of the samples' SE which is 0.7734 , about 50 percent of all.

Table 1. The analysis results of fertilization efficiency of the continuous 3 years cropping greenhouse cucumber

\begin{tabular}{|c|c|c|c|c|c|c|c|}
\hline & $\begin{array}{c}\text { Serial Number } \\
\text { of Field }\end{array}$ & $\begin{array}{l}\text { Technical } \\
\text { Efficiency }\end{array}$ & $\begin{array}{c}\text { Pure Technical } \\
\text { Efficiency }\end{array}$ & $\begin{array}{c}\text { Scale } \\
\text { Efficiency }\end{array}$ & \multicolumn{3}{|c|}{ Redundancy Rates (\%) } \\
\hline \multirow{5}{*}{$\begin{array}{l}\text { Traditional } \\
\text { fertilization }\end{array}$} & 1 & 0.5126 & 0.6771 & 0.7570 & 48.74 & 48.74 & 48.74 \\
\hline & 2 & 0.2123 & 0.4111 & 0.5160 & 78.77 & 82.63 & 78.77 \\
\hline & 3 & 0.2331 & 0.4400 & 0.5300 & 76.69 & 85.69 & 76.69 \\
\hline & 5 & 0.8820 & 1 & 0.8820 & 11.8 & 31.72 & 61.00 \\
\hline & 6 & 1 & 1 & 1 & 0 & 0 & 0 \\
\hline \multirow{4}{*}{$\begin{array}{l}\text { Target yield } \\
\text { fertilization }\end{array}$} & 1 & 0.8328 & 0.9839 & 0.8460 & 22.42 & 0 & 16.72 \\
\hline & 2 & 0.5234 & 0.9802 & 0.5340 & 47.66 & 47.66 & 47.66 \\
\hline & 5 & 0.7266 & 0.9017 & 0.8060 & 27.34 & 0 & 27.34 \\
\hline & 6 & 1 & 1 & 1 & 0 & 0 & 0 \\
\hline \multirow{6}{*}{$\begin{array}{l}\text { Mathematical } \\
\text { model } \\
\text { fertilization }\end{array}$} & 1 & 1 & 1 & 1 & 0 & 0 & 0 \\
\hline & 2 & 0.6467 & 1 & 0.6467 & 35.33 & 0 & 35.33 \\
\hline & 3 & 0.5589 & 0.8716 & 0.6410 & 44.11 & 0 & 44.11 \\
\hline & 4 & 0.6846 & 0.8952 & 0.7650 & 31.54 & 31.54 & 34.92 \\
\hline & 5 & 0.9746 & 1 & 0.9746 & 2.54 & 0 & 25.53 \\
\hline & 6 & 1 & 1 & 1 & 0 & 0 & 0 \\
\hline
\end{tabular}

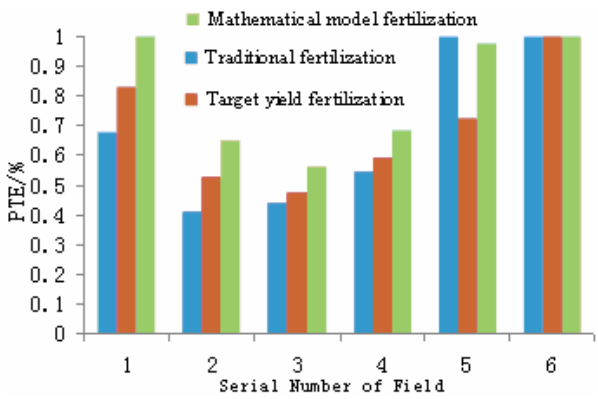

Fig. 2. The pure technology efficiency of the continuous 3 years cropping greenhouse cucumber

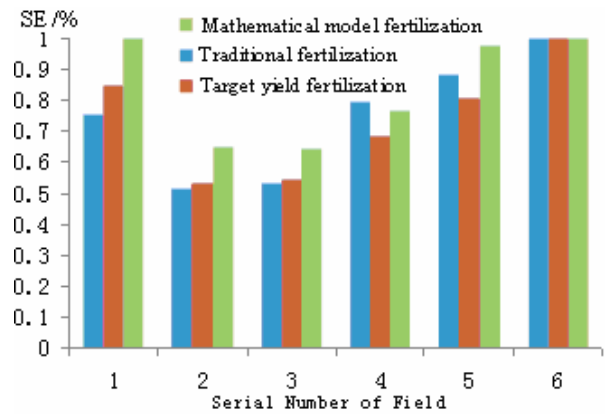

Fig. 3. The scale efficiency of fertilizer-output of the continuous 3 years cropping greenhouse cucumber 
Regarding the average of efficiency, the average of pure technical efficiency is the maximum (0.8579), the scale efficiency second, and the technical efficiency the minimum (0.6826). And the average of redundancy rates of $\mathrm{N}, \mathrm{P}_{2} \mathrm{O}_{5}, \mathrm{~K}_{2} \mathrm{O}$ is $32.06 \%$, $26.56 \%$ and $36.67 \%$ respectively, which can led to the preliminary inference that the unreasonable degree of the inputs was in the increasing order of $\mathrm{P}_{2} \mathrm{O}_{5}, \mathrm{~N}, \mathrm{~K}_{2} \mathrm{O}$.

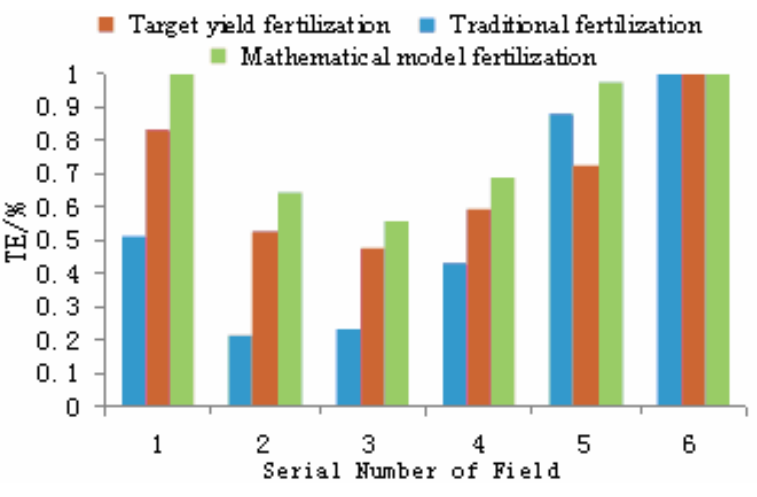

Fig. 4. The technical efficiency of the fertilizer-output of he continuous 3 years cropping greenhouse cucumber output

\subsection{The Fertilization Efficiency with the Consideration of the Diversity of Fertilize Methods}

In the table 2, the fertilization efficiency of three types of fertilization was analyzed. According to the figure2, figure 3 and figure4, the average of TE, PTE, SE of mathematical model fertilization are obviously highest $(0.8108,0.9611,0.8379$, respectively) among that of target yield fertilization and traditional fertilization. And the fertilization efficiency of target yield fertilization is the second highest with that of traditional fertilization following behind. Furthermore, the average of redundancy rates of the three fertilize methods were also showed in table 2. Obviously, the average of redundancy rates of $\mathrm{N}, \mathrm{P}_{2} \mathrm{O}_{5}, \mathrm{~K}_{2} \mathrm{O}$ were the lowest $(18.92 \%, 5.26 \%, 23.32 \%$, respectively) while using mathematical model fertilization. And the average of redundancy rates of target yield fertilization comes next while that of traditional fertilization turns out to be the maximum.

Table 2. The comparison of the fertilization efficiency of three fertilize methods

\begin{tabular}{lcccccc}
\hline & $\begin{array}{c}\text { The } \\
\text { Average } \\
\text { of TE }\end{array}$ & $\begin{array}{c}\text { The } \\
\text { Average } \\
\text { of PTE }\end{array}$ & $\begin{array}{c}\text { The } \\
\text { Average } \\
\text { of SE }\end{array}$ & \multicolumn{2}{c}{$\begin{array}{c}\text { The Average of Input Redundancy } \\
\text { Rates }(\%)\end{array}$} \\
\cline { 6 - 8 } & 0.5455 & 0.6790 & 0.7465 & $\mathrm{~N}$ & $\mathrm{P}_{2} \mathrm{O}_{5}$ & $\mathrm{~K}_{2} \mathrm{O}$ \\
\hline Traditional Fertilization & 0.6915 & 0.9338 & 0.7357 & 31.80 & 23.51 & 30.85 \\
Target yield Fertilization & 0.8108 & 0.9611 & 0.8379 & 18.92 & 5.26 & 23.32 \\
Mathematical Model & & & & & & \\
Fertilization & & & & & &
\end{tabular}

\section{Conclusions}

The fertilizer efficiency of continuous cropping greenhouse cucumber was researched by using DEA. Based on two assumptions $\left(\mathrm{N}, \mathrm{P}_{2} \mathrm{O}_{5}, \mathrm{~K}_{2} \mathrm{O}\right.$ are the major factors that 
affect the yield levels of greenhouse cucumber. For different planting years and seasons, soil nutrient of different plots is the same) and the analysis of technical efficiency, pure technical efficiency, scale efficiency and redundancy rates of three types of fertilization methods, it can come to conclusion that the fertilizer efficiency of mathematical model fertilization is the highest, and the second is target yield fertilization(the exception was that the average of SE lower than that of traditional Fertilization) while the traditional fertilization is the lowest.

\section{References}

1. Wang, L., Zhang, Y., Zhai, C., et al.: Effect of Balanced Fertilization on Yield and Quality of Sunlight Greenhouse Cucumber and Soil Characteristics under Continuous Cropping. Chinese Journal of Eco-Agriculture 16(6), 1375-1383 (2008)

2. Chrnes, A., Cooper, W.W., Rhodes, E.: Measuring the Efficiency of Decision Making Units. European Journal of Operational Research, 429-444 (1978)

3. Qin, S., et al.: Principle and Application of Comprehensive Evaluation. Publishing House of Electronics Industry, Beijing (2003)

4. Wei, Q.: Data Envelopment Analysis. Science Press, Beijing (2004)

5. Chen, L., Lu, J.: Fertilizer Application Technique on Vegetable Nourishment. China Agriculture Press, Beijing (2002)

6. Zhang, Y., Zhai, C., Li, Q., et al.: Study on the Optimum Fertilization Technology of Cucumber. Journal of Hebei Agricultural Sciences 9(1), 75-78 (2005) 